\title{
De los árboles y la pantalla: la amistad viril a través de Alberto Nin Frías y Gabriela Mistral
}

Of trees and the screen: the virile friendship through

Alberto Nin Frías and Gabriela Mistral

Das árvores e da tela: a amizade viril através de

Alberto Nin Frías e Gabriela Mistral

\section{Elizabeth Horan}

ARIZONA STATE UNIVERSITY, ESTADOS UNIDOS

Profesora en el Departamento de Inglés en la Universidad del Estado de Arizona; PhD, UC Santa Cruz. Especialista en escritura de mujeres, estudios de género y traducción, con énfasis en la producción de/ sobre Gabriela Mistral. Entre otros volúmenes de su autoría, destacan Motivos: The Life of San Francis (Bilingual, 2013), Esta América nuestra: correspondencia de Gabriela Mistral y Victoria Ocampo (Cuenco de Plata, 2007), This America of Ours: The Letters of Gabriela Mistral and Victoria Ocampo (University of Texas P, 2003, coeditado con Doris Meyer); House of Memory: Stories by Latin American fewish Writers (The Femenist Press at CUNY, 1999, con Marjorie Agosín); The Subversive Voice of Carmen Lyra: Selected Writings (UP of Florida, 2000) y Gabriela Mistral: An Artist and her People (OAS, 1994). Correo electrónico: elizabeth.horan@asu.edu

Artículo de reflexión

Texto inédito escrito en inglés y traducido al español por Cristián Opazo. La autora agradece los aportes bibliográficos sobre Nin Frías, conservados en la Biblioteca Nacional del Uruguay, que le facilitó Carla Giaudrone. A ella le agradece, también, la generosidad demostrada en conversaciones e intercambios de ideas.

Documento accesible en línea desde la siguiente dirección: http://revistas.javeriana.edu.co doi:10.11144/Javeriana.cl21-42.apav 


\section{Resumen}

Este trabajo rastrea archivos epistolares de Gabriela Mistral, poniendo especial énfasis en las marcas que sitúan a emisores y destinatarios en tiempos y espacios queer. Concentrada en la etapa inicial de su carrera, la pesquisa demuestra cómo Mistral ensaya estrategias retóricas que le permiten escenificar un tipo de amistad queer (amistad viril) y cómo, a partir de ellas, establece relaciones de intercambio afectivo (queer sociability) con intelectuales de las Américas; en especial, Alberto Nin Frías, su primer amigo diplomático y abiertamente homosexual.

Palabras clave: Gabriela Mistral; Alberto Nin Frías; amistadaspectos culturales; cartas; queer sociability

\section{Abstract}

This work traces Gabriela Mistral's epistolary files, with a special emphasis on the signs that place senders and receivers in queer times and spaces. Focused, as she was, on the initial stage of her career, this research demonstrates how Mistral rehearses rhetorical strategies that allow her, first of all, to stage a type of queer friendship (virile friendship) and, from there, establish relationships of affective exchanges (queer sociability) with scholars from the Americas, particularly with Alberto Nin Frías, her first diplomatic and openly homosexual friend.

Keywords: Gabriela Mistral; Alberto Nin Frías; friendshipcultural aspects; letters; queer sociability

\section{Resumo}

Este trabalho rastreia arquivos epistolares de Gabriela Mistral, dando especial ênfase nas marcas que colocam a emissores e destinatários em tempos e espaços queer. Focada no estagio inicial da sua carreira, a indagação mostra como Mistral ensaia estratégias retóricas que lhe permitem, primeiro, encenar um tipo de amizade queer (amizade viril), e, a partir daí, estabelece relacionamentos de troca afetiva (queer sociability) com intelectuais das Américas; especialmente, Alberto Nin Frías, seu primeiro amigo diplomático e abertamente homossexual.

Palavras-chave: Gabriela Mistral; Alberto Nin Frías; amizadeaspectos culturais; cartas; queer sociability

RECIBIDO: 15 DE JULIO DE 2016. ACEPTADO: 22 DE NOVIEMBRE DE 2016. DISPONIBLE EN LÍNEA: 29 DE DICIEMBRE DE 2017

\section{Cómo citar este artículo:}

Horan, Elizabeth. "De los árboles y la pantalla: la amistad viril a través de Alberto Nin Frías y Gabriela Mistral". Cuadernos de Literatura 21.42 (2017): 119-144. https://doi.org/10.11144/Javeriana.cl21-42.apav 


\section{Introducción}

Gabriela Mistral, quien se convertiría en Premio Nobel, aprendió a escribir sobre y hacia el deseo masculino imitando al escritor y diplomático uruguayo Alberto Nin Frías (1878-1937). Él fue su primer amigo abiertamente queer o, como él mismo lo hubiese dicho, su amigo urano. Nin Frías es a menudo reconocido por haber publicado, en español, las primeras representaciones celebratorias, ya no apologéticas, del amor homosexual: Alexis o el significado del temperamento humano (1932) y Homosexualismo creador o la amistad a lo largo de las edades (1933). La amistad e intercambio de correspondencia entre Mistral y Nin Frías nació en enero de 1912, dos décadas antes de la aparición de estos textos tan ampliamente difundidos. Él era una década mayor que ella y contaba con diez libros en su haber. La profesora de escuela de veintitrés años, en cambio, era virtualmente desconocida más allá de su natal provincia de Coquimbo. En este punto de su carrera aún no era conocida por su seudónimo de Gabriela Mistral, sino por su nombre de nacimiento, Lucila Godoy. Entonces, ella buscaba un mentor y, por lo tanto, había ensayado intercambios de correspondencia con varios escritores reputados; sin embargo, sus cartas a poetas chilenos habían fracasado en el intento de conseguir respuestas con comentarios críticos sobre su escritura. Ni el anarquista y teósofo Alejandro Escobar Carvallo, ni el poeta modernista y patriota Antonio Bórquez Solar le ofrecieron en ese momento un vínculo de colaboración y entendimiento mutuo como el que la escritora chilena halló, enseguida, en su amistad con Nin Frías. A juzgar por la correspondencia, esta amistad se prolongó desde 1912 hasta, por lo menos, 1924 .

La evidencia epistolar de la amistad entre Mistral y Nin Frías comienza con una carta hasta ahora ignorada por los estudiosos de la biografía y la obra de ambos autores. Mistral se dirige a Nin Frías desde Antofagasta, en pleno salitre, para alabar su impresionante y original $E l$ árbol (1909, 1910). Más tarde, ambos se conocerían en persona y pondrían en marcha un trabajo colaborativo durante los dos años de la residencia diplomática de Nin Frías en Chile. A pesar de la indiferencia o la sutil oposición del editor de entonces de Mistral, Manuel Guzmán Maturana, quien suprimió este proyecto conjunto, y a pesar de los muchos traslados de Mistral y Nin Frías, la amistad epistolar entre los dos autores continuó por al menos una década. El estudio de esta colaboración y de las cartas tempranas entre Mistral y Nin Frías revela una intersexualidad lejana a los epítetos despectivos que, en esa época, son habituales para los sujetos queer (e.g., invertido), y, además, exhibe cómo se intersectan sus redes, precisamente, queer. 
El afán primero de este ensayo es reflexionar sobre la amistad de ambos y mostrar cómo el idealizado homoerotismo de Nin Frías impactó directamente en la escritura temprana de Mistral, incluso antes de que ella se contactara con Darío o Nervo. La influencia directa de Nin Frías está muy presente en las primeras poesías maduras e internacionalmente reconocidas de Mistral, en la figura andrógina de "El ángel guardián" (1912), en la estética de "La defensa de la belleza" (1913) y, sobre todo, en la intersexualidad central de su "Himno al árbol" $(1913,1914)$. El impacto de Nin Frías en la escritura de Mistral proviene, con mayor fuerza, de $E l$ árbol y sus consideraciones sobre el folclor, la androginia y el compañerismo. También, muy pronto le fueron entrañables las dos novelas tempranas de Nin Frías sobre la utópica amistad homoerótica: Marcos, amador de la belleza, o, la casa de los sueños: novela de un discípulo de Platón durante el Renacimiento (el libro del alma hermosa) (1911) y Sordello Andrea, sus ideas y sentires (novela de la vida interior) (1912). Mistral alaba estas novelas no solo en sus cartas a Nin Frías sino, además, en su epistolario con el conocido pedagogo Maximiliano Salas Marchán, datado en 1913. Más aún, ella sigue impresionada por estas representaciones noveladas de la amistad viril, todavía en 1915, momento en que escribe sus cartas más provocativas al poeta Manuel Magallanes Moure. La influencia de Nin Frías — quien conocía íntimamente el helenismo de Walter Pater y el prerrafaelismo de autores como Swinburne - es, asimismo, fuente del platonismo que subyace en el "Decálogo del artista" de Mistral. La amistad viril escrita por Nin Frías le dio a Mistral una alternativa a la feminidad pasiva que ella rechazó en el diálogo con sus interlocutores. De paso, dicha amistad viril la convirtió en la única escritora chilena que consiguió extender su radio de impacto más allá de una consabida red de pedagogos y, con ello, logró dirigirse a la vanguardia de aquel grupo homosocial de artistas santiaguinos conocidos como Los Diez, o El Innumerable.

El tiempo y el espacio queer — así como el trauma que se relaciona con ellos - son factores que Jack Halberstam distingue cuando escribe sobre las vidas de sujetos queer y transgéneros en ámbitos rurales, distanciándose así de la identificación común y apresurada de la disidencia sexual con contextos urbanos. La indagación sobre la disconformidad sexual de Mistral durante su vida en provincia supone un reconocimiento del lenguaje-código que ella y sus interlocutores queer utilizan de manera evidente; piénsese en los epistolarios de Mistral con Eugenio Labarca y Alberto Nin Frías, entre otros. Mientras vive en Coquimbo, por ejemplo, para decir y no decir, maneja códigos lingüísticos que incluyen, entre otros elementos, citas a las blasfemias de Vargas Vila - a las 
que ella es aficionada-, además del uso de géneros literarios tales como la carta íntima, la página de diario o los versos de álbum; con ellos, se dispone a atraer a los que ella llamaba seres afines. Recuérdese que tanto los epistolarios como los géneros literarios asociados con la cursilería son, en la vida de las provincias, modos y signos de sociabilidad queer.

Dentro de la biografía de Mistral, su amistad con Nin Frías involucra a múltiples grupos vinculados por amigos que, de otro modo, estarían apenas conectados. Mapear la relación del cuerpo de sus correspondencias con sus publicaciones permite resaltar patrones de influencias y redes homosociales antes invisibles. También, este mapeo revela cómo el tiempo y el espacio queer interfieren en las explicaciones del trauma que cada escritor enfatiza en sus narraciones autobiográficas. Más aún, esta enmarcación del trauma individual transforma las representaciones autobiográficas, escritas y performadas, en auténticos debates y memoriales colectivos en torno a los derechos humanos.

Una biografía que se desarrolla mediante la recopilación sistemática (cronológica) de la correspondencia y de las publicaciones representa una aproximación nueva en el ámbito de los estudios mistralianos, ya que revela las variadas formas y maneras que adquieren las influencias y las redes queer, precisamente, en la vida de Mistral. Este método concentrado en las redes y en los años tempranos de Mistral expande la perspectiva que Licia Fiol-Matta propone en "A Queer Mother for the Nation Redux" respecto a la relación que mantuvo la propia Mistral con Doris Dana en la etapa tardía de su vida: "[W] hether the two women had an affair is not, in my view, the most important point; it's the query after a world of queer women intellectuals and travelers, one of whom was gifted and famous, particularly masculine, and everywhere murmured about" (48). La exclusiva periodística de Elisa Montesinos publicada en La Tercera y el documental Locas mujeres de María Wood Montt condujo la atención pública al abundante archivo que respaldaba aquella línea de investigación. La de Dana y Mistral no era una pareja aislada, burguesa, de ritos frívolos o autocomplacientes: decenas de personas trabajaban tras bambalinas para producir y mantener el espectáculo de Gabriela Mistral durante los últimos años de la poeta en el Nueva York de mediados del siglo XX. Por ello, sigue siendo importante localizar e interpretar los archivos fragmentados, muchas veces suprimidos que documentan el salto a la fama de Mistral, contra todo pronóstico, en un tiempo queer (en Chile, en las primeras décadas del siglo XX) y en un lugar igualmente queer (desde lo rural y provinciano hasta la diplomacia errabunda). Contar, aquí, la historia de la 
amistad entre Mistral y Nin Frías - un pionero de la escritura homosexual en español- es un gesto que contribuye a hacer esta historia visible.

El análisis de la relación de Mistral con Nin Frías muestra cómo la poeta chilena practicó, desde el inicio de su fama, la consabida maniobra de apropiarse de las estrategias de los hombres queer. Esta apropiación es manifiesta en aquellas obras de Mistral enfocadas en figuras andróginas o intersexuales y acompañadas, consecuentemente, de un rechazo de las conceptualizaciones de lo femenino como un estado de subordinación abyecta y pasiva. El movimiento hacia la androginia antecede en más de cinco años a la fascinación por la maternidad que la crítica, post hoc, proyecta en la poeta. La maternidad mistraliana - eje de su recepción crítica según detalla de manera convincente Fiol-Matta - no comenzó sino hasta 1919, cuando emerge — si se me permite el chilenismo - como una pantalla o, como se dice en inglés, como a beard: el hombre o la mujer que un individuo utiliza como recurso para cubrir o disfrazar su homosexualidad. Para resumir: la presencia de Mistral en el enclave provinciano y rural de Los Andes, entre 1912 y 1918, es bastante queer. La sociable "hermano Gabriela", una figura puente entre las densas redes fraternales y homosociales chilenas, tiene poco que ver con la maternidad y, por lo tanto, nos hace preguntarnos, ¿de qué tipo de nación sería ella la madre queer?

\section{Cómo hacer cosas con cartas}

El estudio de la correspondencia literaria es invaluable para descubrir relaciones de poder, formales e informales, así como los planes, negociaciones y formalizaciones de, por ejemplo, publicaciones y expectativas de trabajo. Las cartas también expresan emociones que establecen lazos recíprocos entre el escritor y el destinatario. Como la carta es un modo inherentemente relacional, nominalmente privado, las colecciones de cartas son óptimas para escudriñar en el género y en la sociabilidad. Sean estas artificiosamente hilvanadas o surgidas desde las zonas liminales de la consciencia, las cartas ensayan identidades sexuales no dichas o estigmatizadas. Estos dramas improvisados, ensayados o insinuados, se despliegan a través del proscenio de la página escrita. Si un poema lírico modernista es como una fotografía, un momento único compuesto, montado o congelado en el tiempo, la correspondencia epistolar, que abarca muchos miles de planos, es como una imagen en movimiento.

Los múltiples intercambios epistolares que la escritora chilena inició con hombres influyentes cuando ella estaba en el umbral de la fama no es- 
capan a esta máxima de la imagen en movimiento. Todos estos intercambios comienzan con entusiastas elogios a las obras de los destinatarios - con ellos, señala el valor que dichos textos tienen para su propia práctica docente $y$, también, para los profesores en general-. Una vez recibida la respuesta de sus interlocutores, la profesora de escuela procedía a enviar otra con aún más elogios; en ella, de paso, les pedía el envío de un retrato. Ya en su tercera intervención, ella les solicita comentarios sinceros sobre sus propios avances de escritura, pidiéndoles que no la trataran como mujer, con el género de su solicitud consecuentemente alterado, evitando la marca de la primera persona gramatical femenina o volteándose, sin rodeos, hacia la tercera persona masculina, al hacer referencia a sí misma. Así, por ejemplo, en sus primeras cartas al poeta Antonio Bórquez Solar, que datan de 1911 y 1912, incluye varias páginas en las que borra las marcas de género. En el fragmento que transcribo enseguida, Lucila Godoy - aún no convertida en Gabriela Mistral-interpela al mencionado Bórquez Solar:

Olvide Ud. que es una mujer quien le escribe, y dispénsele la ternura que dispensara a un alma cualesquier, siempre que fuera en verdad, un alma. Flammarion dice que las almas no tienen sexo... Vea Ud. que entre muchos yo a Ud. elijo para que la verdad por su boca me sea dicha.

La atención forense a la cronología, la reutilización de un arsenal de frases y la cita constante de ciertos nombres revelan esta estrategia de autorrepresentación, también, en las cartas que dirige a Manuel Magallanes Moure, en 1915: la revisión de las cartas originales muestra que, a diferencia de las versiones publicadas, Mistral evita las marcas de género femenino y las formas que la puedan presentar como mujer. Como se hace palpable, lo queer satura sus cartas y sus relaciones desde las primeras décadas del siglo veinte.

\section{Vidas, tiempos y espacios queer}

El reconocimiento de las identidades, voces y vidas de aquellos que han sido acusados de ser inmorales o enfermos contribuye a combatir la discriminación sexual. La discriminación y los derechos no son enfermedades ni vicios, como Óscar Contardo apunta en los capítulos finales de Raro (2011), texto que constituye un punto de partida clave para la historia de las luchas de los sujetos queer y transgéneros en Chile. Contardo, como Halberstam, reconoce que escribir acerca de las vidas y redes queer supone prestar atención sostenida a los actos de nombrar que confieren existencia a las identidades. Por eso, Halberstam provee un lexicón, define términos y, también, señala 
que "the gender ambiguous individual today represents a very different set of assumptions about gender than the gender inverted subject of the early $20^{\text {th }}$ century" (Halberstam 18). Así, la voz inversión sexual introduce un diagnóstico médico; la voz homosexual, uno criminológico. El trabajo de Nin Frías, tanto de juventud como de madurez, propone una ruta diferente. Durante su adolescencia en Londres, Nin Frías fue testigo de la absoluta hipocresía moral que criminalizaba la homosexualidad:

Joven prodigio, vástago privilegiado de la burguesía económica y política uruguaya de la época, de origen catalán (El Vendrell), Alberto creció en Inglaterra, donde ejercía su padre de embajador de su país tras perder las elecciones a la presidencia, en una espaciosa mansión situada a las puertas de los bosques de Windsor, que dejaron en él una huella indeleble. (García Pérez 44)

En 1895, Nin Frías estaba en la mitad de su adolescencia, justo en medio de la atención general que suscitaba el juicio de sodomía y "conducta indecente" que enfrentaba Oscar Wilde.

Treinta y dos años después, el capítulo de Nin Frías sobre Wilde en Homosexualismo creador parece conflictuado. Él se siente cómodo con la idealización que hace W. Pater del heroico, angélico y andrógino atleta griego, el efebo que se encuentra en el arte figurativo del Renacimiento italiano, en oposición a Wilde, "el mártir del moderno Uranismo" (Nin Frías citado en Hagius 37). Pero la valorización de Nin Frías de la antigüedad grecorromana trasciende este binarismo argumentando que el escritor desarrolla:

una vía de exaltar y dignificar un tipo de relación condenada por el influyente discurso médico-legal. [...] Las ficciones de Alberto Nin Frías publicadas a partir de 1910 rescatan esta otra cara del helenismo, menos iluminada y de límites más bien borrosos que el racionalismo francés había preferido suprimir. (Giaudrone 99)

Con estas mismas publicaciones y en esa misma coyuntura, Nin Frías atrajo la atención de Mistral con el modelo grecorromano de amistad viril, que fue también su introducción a la laxa estética platónica, tan evidente en su correspondencia y en Desolación (1922). En lo sucesivo, la amistad viril será preferida por la poeta en desmedro del modelo francés de homosexualidad en tanto deseo individual que, enseguida, predominó en Latinoamérica.

El nombre de Wilde permanece como un leitmotiv para Nin Frías, en especial, cuando llevó a cabo una extensa e intensa correspondencia con 
Unamuno durante la primera década del siglo XX. Nin Frías usó el nombre de Wilde para indagar sobre una posible identidad uránica de Unamuno; pero este, sin más, respondió:

Conozco el De Profundis de Wilde. Le leí hace tres o cuatro años, y recuerdo que me dejó una honda impresión, aunque con cierto dejo de artificialidad. No hay modo de saber cuándo son sinceros estos hombres en quienes es sincerísima la afectación. El actor ha llegado a suplantar el hombre. (105)

Lo cierto es que Mistral estaba agradecida con Nin Frías por ser un atento interlocutor, educado en Europa, Inglaterra y Estados Unidos, erudito en literatura inglesa y en arte italiano renacentista. La amistad y trato familiar de Nin Frías con escritores del modernismo uruguayo era un punto de fascinación para la profesora de escuela quien, justo un año antes, en 1911, lo había mencionado como su primera filiación literaria, tal como se observa en su primera carta dirigida a Bórquez Solar: "[d] esde Coquimbo, mi tierra, un grupo de muchachos dados a la lectura de los modernistas, y entre los que iba a representar el sexo eminentemente prosaico, sentía yo el deseo vehemente de comunicarme con Ud". Por contraste, ninguna de las comunicaciones de Mistral con Nin Frías presenta la lucha en contra de la especificidad del género gramatical que sí se encuentra en sus comunicaciones con Bórquez Solar.

No cabe duda de que Nin Frías le ofrece a Mistral una expectativa prometedora en su búsqueda de un mentor. Él ya había publicado diez libros sobre religión, filosofía, literatura y temas sociales. También, acababa de obtener un posgrado y había enseñado en universidades de Estados Unidos y Uruguay. Además, en $E l$ árbol, revelaba su resuelta perspectiva latinoamericana. Incluso, Nin Frías le habría prestado a Mistral poemas de su amigo, el poeta maldito Julio Herrera y Reissig, recientemente fallecido de tuberculosis (más tarde, Mistral publicaría uno de ellos en sus Lecturas para mujeres, 1923). En el poema "Recepción", de Herrera y Reissig, la dedicatoria a Nin Frías hace referencia a su uranismo dentro de una nube de referentes míticos y celestiales:

$$
\begin{aligned}
& {[\ldots] \text { el Orbe }} \\
& \text { se embriaga uránicamente } \\
& \text { de los besos de la noche }
\end{aligned}
$$

Alberto Nin: tú has pasado por el Citarón. Mil voces 
te han acogido. Tú has hecho

temblar los antiguos robles. (15)

"No puedo apartarme de su ritmo olímpico", le dijo Herrera y Reissig a Nin Frías, quien respondió llamándose a sí mismo "Adonais" (Herrera y Reissig, y Nin Frías citados en Hagius 17).

Como indica Giaudrone en un estudio iluminador, el uranismo y el culto al efebo son los medios por los cuales Nin Frías representa el amor entre hombres "sin ansiedad ni pánico, como un medio válido de reflexión cultural" (100). Todavía falta una representación semejante para la identidad estigmatizada de las lesbianas. Así lo vemos en el incidente en torno a Safo que casi destruye la amistad entre Nin Frías y la poeta María Eugenia Vaz Ferreira. De entre todos los amigos de Nin Frías, Mistral estaba fascinada con Vaz Ferreira, quien había trabajado y luego enseñado en la recientemente inaugurada Universidad de las Mujeres. Más aún, ella había escrito el prólogo que antecede la novela autobiográfica de Nin Frías, Sordello Andrea, pieza muy admirada por Mistral. Es probable que Nin Frías no le dijera nada a Mistral sobre aquel incidente en torno a Safo, que ocurrió entre 1902 y 1905, cuando él había acordado asesorar a Vaz Ferreira en la preparación de sus poemas así como en la publicación de los mismos. Aparentemente, Nin Frías sugirió, en una carta ahora perdida, que Vaz Ferreira emulaba el ejemplo de Safo. Vaz Ferreira respondió con lo que ella misma llamó "una de las terribles tempestades que más [...] han sacudido [a su espíritu] [...] Safo fue una mala persona", refiriéndose a "aquella gloriosa e inconveniente dama" y a "su vida desordenada y trágica muerte" (Vaz Ferreira). Con todo, Vaz Ferreira condenó su "sugestión maligna" aun cuando ella se disculpó después de recibir la suave respuesta de Nin Frías (que tampoco sobrevivió). Vaz Ferreira retrucó que Nin Frías, como hombre, no podía dirigirse a ella de esa manera: a pesar de mi carácter independiente y despreocupado, o tal vez por eso mismo, tengo por la respetabilidad femenina, como yo la entiendo, una susceptibilidad casi enfermiza. [...] Pensar que Vd., por quien siento una grande y sincera estimación, supusiera que a mí se me podía hablar de Safo (apenas sé de ella que tenía genio y se portaba mal) me causó gran dolor.

Antes de invocar "la respetabilidad femenina" y de sugerir "una susceptibilidad casi enfermiza", Vaz Ferreira establece el contexto de su posición. La hipervigilancia del qué dirán es el precio que debe pagar dado su estatus de educadora. Como Mistral, Vaz Ferreira se presentó como una poeta osada 
que caminaba sola por Montevideo, a veces usando ropa de hombre, y que también interpretó sus propias composiciones musicales en público. Lamentablemente, a fines del siglo XIX, los periódicos de los países del Cono Sur dan pocos ejemplos de estas performances de virilidad. Mistral y Vaz Ferreira viven en una época en la que la figura de la lesbiana era un constructo literario dentro de "titillating and moralizing tales written by men and solicitous of male voyeurism" (Fojas 133). De ahí que la coquette sea la característica que define los Cuentos lésbicos del Diario de la Marina (1864) de La Habana, y de "El corte melena de la amante lésbica" de La Vanguardia de Buenos Aires (1912). Mistral parece estar enterada de tales cuentos, ya que, entonces, en sus cartas a Enrique Labarca, incluye ligeras referencias a los relatos con influencias francesas, de Enrique Gómez Carillo, los cuales, justamente, incluían cuentos lésbicos. Así, por ejemplo, al excusarse por su hábito de enviar cartas kilométricas, Mistral escribe a Labarca: "Ud. que tiene tanto de Gómez Carrillo" y "Ud., francés, gomezcarrillesco, beneventiano, cómo abominará de este pesado e inacabable [hábito]" (Mistral, Epistolario 22, 41). El nombre propio de Gómez Carrillo aporta, pues, un término que en la epistemología del clóset permite aludir a la sexualidad de Labarca, quien ha sido descrito como gay por Virginia Vidal.

La presencia insospechada de sujetos queer y transgéneros en el ámbito rural o provinciano es notable en la correspondencia de Mistral con Labarca y con Nin Frías. Dichas cartas desafían el supuesto de que tales identidades son fundamentalmente urbanas. La preferencia de Mistral por lo rural es bien conocida. Tal como escribe en una carta dirigida a Labarca, necesita la naturaleza de la ruralidad para poder vivir: "árboles, mucho cielo y muchos árboles... ¡Solo los ricos tienen en esa [ciudad de Santiago] estas cosas!" (Mistral, Epistolario 39). A Mistral la ruralidad le provee un espacio para esconderse de los peligros de la ciudad: “[a]lgo más que robaría la paz; sería imposible aislarse de todo allí y [...] cómo envenena la vida la mala gente, léase literatos [...] cómo se muerde y se hace toda clase de daños esta casta divina [...]" (Epistolario 39). Y, acto seguido, continúa: "este pueblo, en que a nadie conozco, es propicio a mi resolución de aislarme con mis heridas y con mis desengaños; otro, Santiago, por ejemplo, tendría que cambiar mi rumbo" (Epistolario 40).

Mistral y Nin Frías acostumbran a presentar escapes hacia lo rural dentro de narraciones autobiográficas de recuperación o de refugio ante los traumas del pasado. El ensueño sensual del niño entre los árboles y las nubes es despedazado por la violencia en la escuela y en la ciudad, donde los 
agresores atacan al débil, al outsider. Mistral y Nin Frías transforman estas historias traumáticas en narraciones autobiográficas de rescate y redención cuando el niño sensible se transforma en adolescente. En el caso de Nin Frías, su alter ego y personaje central de su novela Sordello Andrea es, precisamente, un outsider: "[m]e llamaban faty, gordinflón. Un día me atacaron entre varios al salir del colegio. Me defendí, mejor de lo que hubiese supuesto" (Sordello Andrea 123).

A diferencia de la experiencia narrada en Sordello Andrea, donde la redención llega a través de la amistad íntima que el protagonista entabla con un hermoso niño de una clase social más baja, en las primeras publicaciones de Mistral la redención se confunde con la venganza. En "El perdón de una víctima", la artista femenina reconoce el trauma sexual nombrándolo primero como "una calumnia", un término legal que señala tanto una violación (Peña) como una injuria. La figura central gana autonomía al recordar a su atacante, quien muere cuando le pide perdón a su víctima. Los antecedentes de injusticias sufridas por Mistral en el curso de sus agónicas batallas contra la burocracia educacional se originaron como historias orales, las cuales, posteriormente, ella misma trabajó en sus cartas y en sus viajes a conferencias. Tales anécdotas le sirvieron para un sinfín de propósitos, entre ellos, ganarse la simpatía de los oyentes que sentían también que habían sido privados de toda posibilidad de ejercer su agencia y su poder: así, "la perpetua expulsada" se convirtió en su mantra.

\section{Cronología de una amistad}

La primera carta de Mistral a Nin Frías es un fragmento sin fechar que él publicó en 1933 para promocionar su libro El culto al árbol. Se trata de una nueva edición del libro El árbol $(1909,1910)$ que Lucila Godoy, entonces, profesora en Antofagasta, leyó en 1911 o, a lo sumo, a principios de 1912. Aunque el manuscrito original desapareció, el fragmento que Nin Frías publicó permite reconstruir el contexto. En el pasaje ella expresa su admiración por la obra del uruguayo:

¿Quién escribe hoy para los niños? Casi nadie, porque casi nadie es puro para ir a ellos con las manos limpias de concupiscencias literarias y con el alma con olor a rosa [...] Por eso, debemos a Ud., los maestros, mucho afecto, mucha admiración. Me ha sido dado poner su libro en manos de dos profesores de ciencia. Y sé que han enseñado la Botánica de otro modo después de leerlo. Una Botánica con perfume de poema y de Biblia. Cien veces pensé leyéndolo, por cuarta o quinta vez, en escribirle [...] Yo 
que he enseñado conforme a él y lo 'He visto' en mis niñas, creo poder hablar del libro casi como usted; usted no querrá más que yo. (en Nin Frías, Culto 13)

El hecho de que la profesora haya pensado "cien veces" antes de escribirle indica que esta carta es la primera comunicación entre ambos. La retórica inicial y la afirmación del triunfo de la pureza por sobre la concupiscencia puede permitir fechar esta carta a inicios de 1912. La misma retórica y la misma afirmación aparecen en el párrafo introductorio de "Cuentos: oyendo los del kindergarten", que la profesora publicó en El Mercurio de Antofagasta el 14 de enero de 1912:

Sobran los poetas que se deslían en poemas eróticos, sobran también los que hacen apoteosis de la espada y de la coraza; sobran los que lloran sus lepras íntimas revolcándose en el escepticismo. ¿Dónde hay los poetas de los niños? (citado en Bahamonde 27)

Lo que Nin Frías respondió a Mistral nos es desconocido ya que solo dos de sus cartas dirigidas a la poeta parecen haber sobrevivido. Eso sí, sus respuestas con seguridad la alentaron. De otra forma, Mistral no habría aceptado conocerlo cuando él llegó a Chile cerca de septiembre de 1912.

Hay cinco cartas de Mistral a Nin Frías y dos de Nin Frías a Mistral que sobreviven. En conjunto, las cartas muestran que ellos desarrollaron una relación de trabajo como aquella que Mistral siempre quiso establecer con Bórquez Solar. El diálogo epistolar también se extendía a través de poesías, ya que Mistral parece haber respondido a la primera novela de Nin Frías, La fuente envenenada (1908), con un poema en prosa, "Limpia tu fuente". La profesora chilena luego, en su lectura de las novelas autobiográficas de Nin Frías y, después, en sus cartas al escritor uruguayo, delineó a Sordello Andrea - personaje de la novela homónima - en una poesía ahora perdida, "Oración de Sordello Andrea". Sordello, el personaje de Nin Frías que atrae a Mistral, evoca la adolescencia como un espacio utópico para la amistad idealizada: "[t]ocamos el cielo cuando nos ponemos la mano en un cuerpo humano. ¡Cuántas veces permanecíamos dormidos, abrazados, olvidando juguetes, conversación, planes de mañana!" (Nin Frías, Sordello 195). La síntesis de Giaudrone explicita el interés por la adolescencia que Mistral compartió con Nin Frías; precisamente, "[a]l recuperar y validar la perspectiva descentralizada del niño y [el] adolescente, Nin Frías consigue dar expresión a un sujeto cuya manifestación está siempre señalada en términos de amistad viril" (317). 
La ambigüedad sexual del poema de Mistral "El ángel guardián", publicado por primera vez en julio de 1912, muestra cómo un adolescente andrógino se adapta fácilmente a la llamada literatura para niños. La crítica de este poema, desde Belmas en adelante, ha estado mal encaminada, ya sea por el contenido ligeramente disfrazado y medianamente religioso del texto, o por el sentimiento que emana del apelativo "tú" presente en todo el poema, que incorpora a un niño imaginario como oyente. ¿Qué hacer con el tema del sujeto nominal del oyente que se perfila como el perfecto compañero asexual y a quien el poema, descontado el título, evita cuidadosamente asignarle un género gramatical? Las cartas de Mistral al profesor Maximiliano Salas Marchán, quien escribió el libro de gramática que ella usaba, admiten esta forma de acercarse al poema y a otros que ella escribió inmediatamente después de "El ángel guardián": "[y]a en Antofagasta, en Gramática me había hecho pensar seriamente en cuánto se puede hacer por llevar lo bello -la unión divina de las cosas - a los campos más áridos donde solo el aburrimiento tuvo sitio hasta hoy".

Las dos referencias al libro de Salas Marchán se mueven más allá de la lógica de la pantalla para revelar la sintaxis deliberadamente torcida utilizada en este cuento para niños. La sexualidad participa dentro de "la unión divina de las cosas" que Mistral desarrolló en el "Himno al árbol", que publicó en cuatro lugares diferentes, cada uno con un público distinto, entre finales de 1913 y principios de 1914, durante la residencia del diplomático uruguayo en Chile. Ante los lectores de la Aurora de Los Andes, los teósofos, los educadores y la gente que leyó la revista semanal Sucesos, Mistral retrata al árbol como una criatura sintiente, un testigo del tiempo, ajeno al binarismo de género. Cinco años después, sin embargo, las revisiones que hace la poeta le restan importancia al árbol como un ideal de vigor sexual: "[h]azme amoroso para el suelo" se transforma en "[h] azme piadoso para la escoria"; "[s]in que este amor mate el anhelo" se convierte en "sin que se duerma la memoria". ¿Autocensura? El árbol que fue, en 1912, un "universo protector" se vuelve una "dulce entraña de una mujer" en la versión de 1919 que publicó tres años más tarde en Desolación, y que dedicó a José Vasconcelos.

\section{¿Cómo, dónde y cuándo Mistral y Nin Frías se conocieron en persona?}

En julio de 1912 Mistral deja Coquimbo en un viaje en barco de ocho horas con destino a Valparaíso. Antes de continuar a Los Andes, realiza una visita relámpago a la oficina de la revista Sucesos y deja un recado para el editor, Ossandón de la Peña. Él le pide trabajar haciendo reseñas de libros, pero ella 
se excusa alegando su falta de ambición literaria y su necesidad de mantenerse alejada de los escritores de Santiago, incluso, de esos mismos con quienes ella mantenía correspondencia. Sin embargo, Mistral hizo una excepción con Nin Frías. Los dos se conocieron en el mismo barco porque, según cuenta él a un grupo de escritores a los que convoca a un almuerzo de bienvenida en Santiago, nunca había conocido a una mujer más interesante que esta profesora de escuela que empezaba a trabajar en el recientemente fundado liceo de Los Andes. Según Santelices, Nin Frías habría dicho que "[s]u talento es algo que rebasa en su interesante charla; los grandes valores intelectuales del mundo, le son familiares; le he prometido algunos libros y desearía hacerlos llegar a sus manos" (25).

El primer pensamiento de Mistral fue presentar a Nin Frías a los dos educadores más influyentes del Chile de la época, a quienes les había escrito durante 1913. La influencia del escritor uruguayo está presente en la docena de poemas que Mistral le envió al teósofo y gramático Max Salas Marchán (exdirector del Liceo de Hombres de Los Andes). Junto con los poemas, en la carta a Salas Marchán menciona su deuda con la novela autobiográfica de Nin Frías, aunque no nombra al autor: "La Oración de Sordello Andrea' i el 'Credo del Maestro' [...] me dieron mi tendencia de hoy: un misticismo delicado, que - ¡cosa extraña! — va hacia el dulce fesús i no me viene, sin embargo, de ningún libro cristiano".

Incapaz de interesar a Salas Marchán, Mistral comenzó a dirigirse al gestor educacional y editor Manuel Guzmán Maturana, quien rápidamente mesuró el valor de los escritos de la profesora/poeta para sus planes de negocios. En 1905, había montado una editorial y una librería, Editorial Minerva, cuyos textos educativos financiaron la publicación de algunos textos literarios de poetas patriotas como Víctor Domingo Silva y Bórquez Solar. Más que sugerirle desarrollar un libro por sí sola, le solicitó a Mistral ayudarle en un volumen que él estaba editando; por esto mismo, dicho volumen incluye entre cincuenta y cinco y sesenta artículos de ella. "Le hubieron dado un dineral", dijo Mistral después, indicando que además fue ella quien escogió abundante material para él (Vuestra Gabriela 177 ).

Después de uno de sus encuentros con Nin Frías, en 1913, Mistral intentó interesar a Guzmán Maturana en un proyecto que ella y Nin Frías acababan de comenzar, y que ambos siguieron desarrollando: un libro colaborativo basado en El árbol. Ellos habían escrito una glosa en tres partes. Mistral se la dio a Guzmán Maturana, indicándole que Nin Frías debería recibir el máximo crédito por ella. Tales signos de buena voluntad entre sus colegas chilenos probablemente 
ayudaron a Nin Fías a ser ascendido a encargado de negocios. Pero Mistral fue ingenua, o quizá fue un error de Guzmán, quien mandó a imprimir una selección de la glosa en Libros de lectura, pero sin darle crédito a Nin Frías. El editor no logró corregir el descuido hasta la tercera edición, algunos años después, luego de que Nin Frías se contactara dos veces con Mistral acerca del tema, entre la agitación en que se encontraban ambos por aquella época.

La partida de Chile del uruguayo dio lugar a la primera carta que Mistral le envía en 1914, y que ha sobrevivido en su integridad. Una noticia en el diario informó de su traslado a Venezuela. Allí, ella espera que la correspondencia entre ambos continúe, y que el cielo y la nieve de Chile contrarresten todas las dificultades que él había experimentado. Un mes después, su carta desde Caracas no expresaba ninguna desilusión con Chile, sino con la diplomacia: "[e]l Ministro en Chile fue muy falso conmigo y tanto me intrigó que estoy ahora de secretario de 2 da clase. Espero [que] el Gob. futuro repare la injusticia". Tras el cambio de gobierno, cuatro meses después, renunció. La experiencia de Nin Frías probablemente fue determinante para la cautela con que Mistral, años después, poco a poco y con mayor merecimiento que cualquier otro de sus colegas hombres, negoció su propia entrada al servicio consular chileno.

El arribo de Nin Frías a Chile coincide con la decisión de Mistral de escribirle a Rubén Darío alrededor de agosto 1912. La respuesta a su afán fue positiva: Darío publicó su "El ángel guardián" en Elegancias en marzo de 1913. Y, tras su partida, en octubre de 1914, Mistral le comenta a Nin Frías que ella sigue trabajando en sus sonetos:

[i]Recibí su retrato! Muy bella tarjeta. Recuerda usted a sus propios personajes de Marcos [Amador de belleza]. A propósito: los sonetos anunciados irán más tarde; debo pulirlos y estoy ahora muy ocupada en labores materiales... Le he hecho algunos capítulos a El árbol. [...] Sé de mi decir que me deja, con Marcos y con Sordello el pan espiritual de muchos años. Las bellas, las puras cosas, que sobre sus pájinas he soñado y he sentido, han de ir a su espíritu para beneficiarlo, por la ley natural de que la obra $-\mathrm{y}$ sus efectos- dan frutos para el que le infundió aliento. ( $E l$ ojo atravesado 15-16)

Después que Nin Frías se alejó del país, Mistral se contactó con el poeta Manuel Magallanes Moure, el encargado de los Juegos Florales, celebrados en Santiago a finales de ese año. Sucede que Magallanes sería el encargado del voto decisivo para romper un empate entre los otros dos jurados. Como 
es sabido, a la hora de dirimir el primer premio de poesía, Magallanes Moure falló a favor de su nueva amiga epistolar: Gabriela Mistral.

\section{La pantalla, "quizás muy mujer" o "traducir masculinos pensares es difícil"}

Mucha de la correspondencia entre la poeta y Magallanes Moure fue encubierta. Mistral escondía su identidad, incluido su género, por debajo de la "L" que aparece al pie de muchas de las cartas dirigidas a él. Lo que comenzó como un diálogo, pronto, se tradujo en centenares de cartas. De estas, alrededor de ochenta, además de un telegrama dirigido a ella y de cinco cartas o fragmentos de cartas de él, aún sobreviven. El conjunto es "un batido difícil de entender", como la propia escritora dijo de sí misma en otra ocasión (Iduarte 449).

En su correspondencia temprana, L le advertía a su destinatario que él estaba bastante equivocado en sus suposiciones acerca de su naturaleza. Por ello, en una carta temprana se refiere a la sorpresa de Nin Frías en su primer encuentro, y al concepto de árbol que él tenía entendido como el emblema de lo amado, moviéndose desde ahí hasta la homoerótica masturbatoria. Las cartas posteriores exaltan a Magallanes como un epítome de la belleza, en consistencia con la estética queer de Sordello Andrea, dentro de una ideología de amistad masculina homoerótica. Lo más llamativo es que L se expresa dentro de un diálogo sexualizado que rechaza, uno por uno, los intentos del destinatario por clasificar a este interlocutor como una mujer.

La masturbación es el tema de la carta sexualmente más explícita de las que sobrevivieron al paso del tiempo. El contexto de dicha carta es la respuesta de L a dos misivas de Magallanes Moure, fechadas el 1 de marzo de 1915. En la primera misiva, Magallanes intenta alagarla diciéndole que sus poemas no muestran los defectos comunes de las escritoras: "¿[p]or qué será que aborrezco la palabra poetisa? Seguramente por lo que se ha abusado de ella aquí y en toda la América española, al extremo de que ya es una palabra desvalorizada". Después de compararla con Delmira Agostini, en Uruguay, y con Emilia Bernal, en Cuba, él añade la siguiente justificación: "[n]unca he podido tomar en serio a las demás mujeres que hacen versos en tierras indo-españolas" (Magallanes, Manuel 76).

Mistral estaba más que familiarizada con el gesto masculino de desvalorizar a las escritoras, de manera supuestamente cortés, tomando a un puñado de ellas como ejemplo de una clase inferior, para declararla como la excepción a la regla. Alentada por la aclamación recibida en los Juegos Florales, la respuesta de Mistral a las categorías fantasmales de mujer y de lo femenino 
es una fantasía homoerótica arcadiana que prepara la escena: "[t] e escribo desde la orilla del río, en un bosque de acacias jóvenes" (Manuel 77).

Las convenciones de cortesía de los siguientes dos movimientos son requisitos del género epistolar: él se queja de su estado de salud, por lo que corresponde ofrecerle comprensión; la salud de ella también es deplorable. Luego, somos redirigidos al bosque de acacias imaginadas donde ella está leyendo su carta bajo la luz de un sol que se filtra entre las hojas. La respuesta de L coincide y se intersecta con la imagen que la carta encubierta de Magallanes, actualmente perdida, proyecta. L responde, de manera seca, que sus cartas deberían estar dirigidas a su verdadera receptora, a la amiga que él ha imaginado, y no a ella, a quien no corresponden: " $[\mathrm{t}] \mathrm{u}$ carta me ha dado esta impresión: todas estas palabras ardientes y bellas se las dices tú a otra, a alguna amiga mía que es bella. Yo debo entregar esas cartas solamente. Y como en muchos casos de amigas 'protectoras', pasa que yo me he enamorado de ti a fuerza de leer tanta frase seductora, tanta sugestión ardorosa" (Manuel 77).

El uso que hace Mistral de la estrategia de la pantalla duplica lo que ella misma había aprendido en su correspondencia con Alfredo Videla una década antes: la escritora escapa al espacio restringido de lo femenino a través de jugar y proyectar el deseo del destinatario hacia otra mujer, una tercera, imaginada. Esa carta no pertenece a L sino a la mujer que el destinatario imagina; L es una coartada:

[n]o es para mí, no puede ser para mí esta carta, como no lo son las otras que le preceden... tú te has hecho de mí una imagen embellecida, tú le has dado cuanto deseas que tenga y es a esa, a esa que no soy yo a quien escribes y dices querer, o quieres. Yo con esa no tengo nada que hacer, de común sino el nombre. Tú no puedes, Manuel, quererme a mí (77).

Al transformar la escena, la escritora repudia el deseo heterosexual con un guiño a lo real:

Mira, tú que conoces La Serena y otros pueblos antiguos hazte esta imagen: una señora apacible, que se balancea al andar, que usa calzado grande, que no se pone corsé, que anda con ropas anchas, que se echa el pelo atrás, sencillamente, que hace clases como pudiera hacer sermones, que no tiene nada, nada, de ese no sé qué que despierta en los hombres el deseo de ser amadas [sic] por una mujer [...]. (Manuel 78$)$

El repudio de la escritora a la feminidad disecciona lo que el destinatario ha escrito, declarando que la asimila a ella a "una mujer" solo si la otra 
alternativa es un "marimacho". Para reforzar este punto, la escritora provee nombres de hombres bohemios como referentes del mundo real que ella ha conocido en persona:

La feminidad de que tú me has hablado tiene en mí este sello: una mujer, sí, no un marimacho, pero una monja, una abadesa gorda y pacífica. Víctor Domingo Silva dice que tengo cara de pensadora rusa. ¿Verdad que no tiene nada de atrayente el retrato ese? Lo que escribo (cartas, versos) dan una idea errada de mí. Alberto Nin Frías por mis garabatos nerviosos y locos me creía un ser apasionado y quizás muy mujer. [...] Su asombro fue muy grande cuando me trató. La pasión debe existir en mí, existe, pero en capas de alma a donde nadie, absolutamente nadie, quiso bajar a sacarla a flor de... tierra, diré [...]. (Manuel 78 )

El pretender ser una mujer requiere referencias. En contraste con la galantería de Víctor Domingo Silva que la mienta como "una pensadora rusa", está la afectada visión de Alberto Nin Frías, quien la había creído algo completamente diferente, inclasificable: "un ser muy apasionado y quizás muy mujer". La intersexualidad o, por lo menos, el rechazo al binarismo sexual se ve en epítetos que ponen en duda la fijeza de la identidad ("un ser muy apasionado" o "quizás muy mujer"). Al invocar el nombre de Nin Frías, la escritora da paso a la tercera y más elaborada fantasía de la carta. En esa fantasía, ella sugiere la entrega de un beso apasionado al destinario, al "hermano poeta de la barba nazarena", como era el nombre "fraternal" con que Magallanes era conocido entre los hermanos de Los Diez. Contra un tronco de "envoltura negra y espesa", ella llega al clímax:

Oye: estoy acostada contra un tronco. Siempre me ha gustado besar los troncos en sus heridas llenas de goma pálida. Este tronco tiene abajo una envoltura negra y espesa de hilachas que no sé a qué enredadera pertenezcan. Yo acabo de besar el tronco de su herida repleta de goma; pero no es al árbol al que beso, como otras veces, es a ti, amado, a ti. Esta es tu boca. Está tibia, porque un rayo de sol le cae encima. Toda esta enredadera muerta finge una barba negra que roza acariciando. $[\ldots]$ ¿ Serás paciente como el árbol para dejarme exprimirte la goma pálida de tu dulzura, así, así, con este ímpetu tan raro en mí? (79)

La carta continúa: "dime si no soy tuya, tuya, tuya" (79). Pero en 2015, cuando Graciela Huinao, Macarena Urzúa y yo comparamos los manuscritos originales de las cartas - conservadas en la Biblioteca de Humanidades de 
la Pontificia Universidad Católica de Chile-, con las versiones publicadas en Manuel en los labios por mucho tiempo, nos encontramos con muchos cambios curiosos, incluso, cambios de género gramatical que los editores estandarizaron, tal vez, con el fin de dar consistencia a su edición. De puño y letra de Gabriela Mistral, la carta citada arriba dice, por ejemplo, "amadas por una mujer" $y$ "[...] dime si no soy tuyo, tuya, tuya" (Carta 18, PUC 2, 13, 1915). Otro ejemplo: L escribe "[n]o era mujer, era leona", pero la edición publicada añade el pronombre, "yo", feminizándola: "[n]o era yo una mujer, era leona" (Carta 5, PUC2, 9, 1914; Manuel 55). Y la edición, también, añade el sustantivo "mujeres" en la siguiente frase: "tenía una triste idea de las mujeres que en Chile escribíamos" (Carta 17, PUC 1, 2, 1915; Manuel 75).

De todas formas, las cartas a Magallanes Moure no expresan deseo por el destinatario. Más aún, rechazan la feminidad real en favor del despliegue incorpóreo de la fantasía, siendo numerosas las pantallas a las que recurre para decir "este ímpetu tan raro en mî" (79). A su vez, la carta siguiente ofrece una instancia de emergencia para las fantasías sadomasoquistas que aparecen, de vez en cuando, a lo largo de la correspondencia con Magallanes:" [t]e he amarrado las manos, por perversas; te vigilo la boca, por perversa también. Te digo que te quedes quieto y te hablo largo" (Manuel 80).

Lo que separa a Mistral de Magallanes es mucho más que la clase social a la que ella se refiere cuando dice "yo quiero beber tu linfa toda" (Manuel 117). Por su parte, las observaciones de Hurtado proveen el contexto que así lo demuestra: "Gabriela atribuye a Magallanes la calidad de flor natural, de verdadera flor en sentido religioso-místico de "amor a los seres"' (188). Él pertenece a la élite, al espiritualismo de vanguardia, mientras que ella es mucho más peligrosa: "una cuchilla repleta de sombra, abierta en una tierra agria" (Manuel 65). Mientras tanto, Mistral le dice, dos veces, que su "Himno al árbol" "es la poesía donde he puesto mi ideal de perfección" y que lo prefiere a su "El ángel guardián" (Manuel 62, 73).

Para revolver la olla, construir una red y seguir cautivando a este poeta influyente, Gabriela Mistral incorpora a otro jugador. Son impecables las credenciales de Eduardo Barrios: pertenece al grupo Los Diez, pero no proviene de la aristocracia. Como ella, Barrios se gana el pan trabajando por un sueldo mínimo mientras escribe de noche y muy de mañana. Entonces, Barrios acababa de publicar El niño que enloqueció de amor, novela basada en el "caso" de un Magallanes Moure preadolescente, un escritor de una correspondencia encubierta con la que logró cultivar el amor prohibido con su prima Amalia, más de diez años mayor que él. Mistral hizo un soneto premonitorio para El niño que enloqueció de amor y, de manera transaccional, le pidió un favor a Barrios: que él retirara 
el nombre de ella de un concurso de mujeres escritoras, sin decir, por supuesto, por qué. El beneficio que obtendría Mistral con esta maniobra consistía en tener a Barrios como representante; el beneficio para Barrios, en tanto, era conseguir acceder a la red de interlocutores que Mistral estaba cultivando. Por añadidura, él se transformó, en cierto sentido, en un confidente que tomó el lugar que para ella había tenido Nin Frías.

Signo del éxito de la maniobra de Mistral es que ella fue la única mujer incluida en la Pequeña antología de Los Diez (1917) y, por lo tanto, se hizo "merecedora" de ataques y enemigos. Juan Duval, el seudónimo de un conservador aspirante a crítico literario, parodia los versos de Mistral en Sucesos, revista que él recién había comprado. A pesar de los varios amigos que saltaron en su defensa, el crítico imprimió otro artículo, igualmente burlón, una semana después. Mistral, entonces, le dirigió una nota a Barrios donde trata de explicar su frustración y, de paso, admitir la ficción de la pantalla, la ficción de "un amor grande en la vida", la ficción hecha para anticiparse a la acusación tácita de su masculinidad femenina:

A Ud., hermano, a Ud. solito, le confieso por qué este segundo artículo del bribón me ha abatido tanto. ¿ ${ }^{N}$ o ha visto Ud. que en él zarandea a la mujer, a la pobre mujer que debía tener un amor grande en la vida, puesto que no era un marimacho? ¿No ve Ud. que un canalla, con toda esa cosa pura y llameante que el es amor, ha hecho y puede seguir haciendo escándalo y ridículo quién sabe hasta que extremos? [Fin de cita] (Mistral, Carta a Eduardo Barrios, abril-mayo 1917).

Lo que extraña cuando surge un espectro que tilda a la poeta de $m a$ rimacho es que su atacante, Juan Duval, no escribe nada sobre el amor que supuestamente subyace a la situación dramática del poema. Esto nos recuerda lo que escribe Fiol-Matta, citando a Muñoz, sobre el problema de la "evidencia" en los estudios queer: "Central to performance scholarship is a queer impulse that intends to discuss an object whose ontology, in its inability to 'count' as a proper "proof' is profoundly queer" (Muñoz citado en Fiol-Matta 51, n. 34).

Si el amado fallecido es una pantalla, tan fingida y necesaria como lo es el amor en la poesía, entonces ningún cúmulo de cartas, postales o manuscritos será suficiente para probar o negar su existencia. En resumen: la carta individual habla del escritor y sus destinatarios reales y/o imaginados; el epistolario, en tanto, sienta la trayectoria de una relación, mientras que múltiples epistolarios — un cuerpo de correspondencias - revelan las también múltiples dimensiones de esas relaciones a través del tiempo y del espacio. 


\section{Desde México a España}

Las últimas dos cartas de Mistral a Nin Frías están firmadas en México. La más antigua y extensa, fechada el 7 de enero de 1923, marca un momento de libertad sin precedentes. Mistral acababa de escribir a sus amigos en Chile; al aceptar la oferta de Obregón, finalmente, renuncia a su puesto en Chile. En lugar de regresar a la batalla en Santiago, seguiría su trabajo en y para México, incluso desde Europa. En este momento de abandono salvaje, ella hace una pausa para responder una postal de Nin Frías, quien se había transformado en ciudadano argentino y se dedicaba al periodismo en Buenos Aires, alternativa que Mistral había considerado para sí misma antes de aceptar la invitación de México. La gratitud y afecto que Mistral ahora expresa a Nin Frías en su carta de 1923 parecen diseñados estratégicamente para asegurarle futuras publicaciones y empleos. Es, si se quiere, una "carta de recomendación" que él puede hacer circular entre los amigos que ambos comparten en la capital argentina. Además, la carta incluye un reconocimiento de la orientación sexual de Nin Frías en el contexto panorámico de su obra. Ella admite que es un raro aunque sin usar esta palabra: "su mente y su alma son un caso en nuestra América. Nunca será Ud. un autor popular ni siquiera uno difundido. Sus lectores son un grupo escogido de pensadores o de místicos" (Mistral citada en Guerra y Zondek 19-20). Ella continúa: "[t]iene usted lo enjuto y lo rígido del escritor inglés moralista. [...] Es el menos latino de nuestros escritores, en este sentido: no busca para sus ideas el vínculo sensual de la metáfora"(20).

La confianza y generosidad del juicio de Mistral sobre Nin Frías reflejan lo que José Joaquín Blanco describe como la "educación universitaria" que ella obtuvo al trabajar en el México posrevolucionario (107):

Las maneras artísticas de hoy más dominantes en los nuevos son éstas: Una derivada de la literatura rusa: narración seca, movida y sobria y asuntos sociales. Una derivada todavía de la escuela de Zola: prosa coloreada y espesa, que busca copiar la vida. Una muy en boga, traída por Taine: sencillez y naturalidad; transparencia, facilidad. Y otras tomadas de algunos estetas (Gautier y Wilde) atildadura, precisión, refinamiento. Algunos la han aliado con la anterior. Ud. no está en ellas. Su cultura clásica, su acerbo filosófico harán siempre de Ud. el escritor serio, que aleja de su prosa toda intención de poema (grupos zer y 4to), i el espíritu exquisito lo divorcia en absoluto de la escuela naturalista y hasta de la realista. (20)

Luego, ella habla del "mal espiritual" que ella cree que comparten, y le ofrece la cura: "[n]o podemos prescindir de ciertos modos paganos de la vida. Paganismo de la sensibilidad, que da sus mejores jugos al pensa- 
miento". Su carta concluye con más agradecimientos por su obra, sus planes futuros, y una pregunta que vincula la estética de él con la más audaz de las pantallas que ella había proyectado hasta entonces; a saber, una maternidad sin hombres: "¿Leyó esos poemas de la madre, enteros?".

Junto con Diego Rivera, Mistral fue la mejor pagada de entre los muchos empleados en la SEP mexicana (Ministerio de Educación). Entre sus colaboradores estaba Salvador Novo, un joven de diecinueve años con energía ilimitada, abiertamente queer, quien más tarde se convertiría en el cronista oficial de la vida nacional mexicana. Así como la burla que Duval prodigó a Mistral evidenció su llegada a Los Diez, la afectada burla que espeta Novo indicó que la escritora chilena había llegado a ese núcleo de jóvenes mexicanos que estaban actualizando la masculinidad y la homosociabilidad de la cultura nacional. Novo la incluyó en su revista, "un periodiquillo titulado El Chafirete dirigido a dicho gremio. [...] En este semanario de ocho páginas, escrito en el slang de los choferes, Novo utilizó el seudónimo de 'Radiator' para firmar artículos satíricos y burlones" (Barrera 103). Novo inventó una entrevista apócrifa con Gabriela Sidral (alter ego paródico de la poeta chilena) que "la expone a través de una serie de doble sentidos". En ella, Gabriela Sidral le dice a su entrevistador ficticio que no sabe nada sobre las "tortilleras" y observa:

No soy de esas. En mi tierra no se acostumbra... no sé precisamente lo que es ser tortillera. Aunque las conozco: las veo muy seguido en los mercados. En Chile no nos metemos en esos mitotes: para eso no se hizo la lengua. Doblemos la hoja. [...] Qué cochinas, ¿eh? En la república de Chile no se ve eso. El Despachador toca el pito; meto carrera; huyo porque ello halló mi orgullo, hasta el hoyo. De Ustedes afectísima y segura servidora, Gabriela Sidral. (Gallo 28)

La última carta de Mistral a Nin Frías aparentemente data de 1924. Mientras ella se preparaba para dejar México e irse a Europa, ella sella la amistad con su amigo: "[e]s casi seguro que a vuelta de México me iré por el Atlántico y pasaré a la Argentina, entonces reanudaremos nuestra vieja amistad, que no por ser silenciosa deja de ser leal y firme" (Mistral citada en Guerra y Zondek 21). El encuentro probablemente no tuvo lugar: la poeta, una incipiente diplomática, optó por permanecer a bordo del barco en vez de enfrentar las preguntas de la prensa en Buenos Aires, entremedio de eventos políticos tales como el Ruido de Sables en Chile, en aquel enero de 1925.

En el mundo hispanoparlante, la España de fines de la década de 1920 y principios de la de 1930 es el escenario de los cambios más grandes en la concepción del género y la orientación sexual. Esto, según sugiere la publicación de los primeros libros en español de enfoque homosexual explícito. Mistral conocía personalmente 
tanto a Augusto D'Halmar (Pasión y muerte del cura Deusto, 1925) como a Hernández Catá (El ángel de Sodoma, 1929), cuyas novelas presentaban protagonistas reprimidos que vivieron y murieron infelices. Nada más lejos de la erudición y creatividad de libre expresión de las dos publicaciones mayores de Nin Frías (fechadas en 1932 y 1933). Su editor, Javier Morata, estaba ansioso por seguir construyendo una colección a partir de las exitosas ventas de Los estados intersexuales de la especie humana (1930) de Marañón, otro amigo personal de Mistral. Los libros de Nin Frías fueron un éxito y circularon a lo largo de todo el mundo hispanohablante, pero aparecieron en un momento queer: el colapso económico de la depresión cayó sobre el ámbito editorial y la República española encalló en el reaccionario bienio negro.

Las cartas de Mistral dejan ver que ella leyó las teorías influyentes de Marañón sobre la intersexualidad. Aún nada demuestra que leyó la enciclopédica Homosexualismo creador ni el intimista Alexis de Nin Frías. Mistral no tuvo tiempo libre: el consulado la sumergía en la burocracia y obligaciones sociales mientras ella, además, debía mantenerse mediante el ejercicio del periodismo. Mistral parece no haber respondido la breve nota de Nin Frías desde Villa Ballester, un suburbio al norte de Buenos Aires. Él escribió esa nota con el fin de conseguir la dirección de la poeta chilena, para poder enviarle sus libros más recientes. También le pidió a Mistral que acusara recibo de su carta, la que cierra con un enunciado seguido de una pregunta: "[n] uestra Amistad, de la cual siempre me honro, fue un día cosa muy inspiradora y muy bella, ¿por qué no ha de seguir siéndolo?". Si la de la carta es una historia circular, la respuesta a esta última pregunta será hallada en el comienzo; la respuesta será, pues, la consigna o la moraleja no citada que Nin Frías tomó de El retrato de Dorian Gray, de Wilde, y que dejó impresa en su membrete de Villa Ballester: "[t]ras toda cosa exquisita existe algo trágico". Nin Frías murió tres años después en Suardi, Santa Fe, Argentina, bajo el cuidado de Pedro Badanelli, "la sotana española de Perón".

\section{Obras citadas}

Bahamonde, Mario. GM en Antofagasta: años de forja y

valentía. Santiago: Nascimento, 1980. Impreso.

Barrera, Reyna. Salvador Novo, navaja de la inteligencia.

México: Plaza y Valdés, 1999. Impreso.

Blanco, José Joaquín. Se llamaba Vasconcelos: una evocación crítica.

México: Fondo de Cultura Económica 1977, 1993. Impreso.

Contardo, Oscar. Raro: una historia gay de Chile. Santiago: Planeta, 2011. Impreso.

Fiol-Matta, Licia. "A Queer Mother for the Nation Redux: Gabriela Mistral in the

Twenty-First Century". Radical History Review 120 (2014): 35-51. Impreso. 
Fojas, Camila. Cosmopolitanism in the Americas. West

Lafayette: Purdue UP, 2005. Impreso.

Gallo, Rubén. Freud's Mexico: Into the Wilds of Psychoanalysis.

Cambridge: MIT Press, 2010. Impreso.

García Pérez, Guillermo. "El culto al árbol y otras aportaciones hispanas pioneras de Alberto Nin". Boletín de la Sociedad Ateneísta de Aire Libre 44 (2012): 12-21. Web.

Giaudrone, Carla. Degeneración de 900. Montevideo: Trilce, 2005. Impreso.

Hagius, Hugh. Alberto Nin Frías: vida y obras. Trad. Pesce de Bargellini. New York: Bibliogay, 2009. Impreso.

Halberstam, Jack. In a Queer Time and Place. Transgender Bodies, Subcultural Lives. New York: NYU Press, 2005. Impreso.

Herrera y Ressig, Julio. "Recepción". Poesía completa y prosas. Ed. Ángeles Estévez. Madrid: ALLCA XX, 1998. Impreso.

Hurtado, María de la Luz. "La performance de los Juegos Florales de 1914 y la inadecuada presencia de Gabriela Mistral en ellos". Revista Chilena de Literatura 72 (2008): 163-191. Impreso.

Iduarte, Andrés. Gabriela Mistral, Santa a la jineta. México: Cuadernos Americanos, 1958. Impreso.

Mistral, Gabriela. "Carta a Alberto Nin Frías [enero 1912]" y "Fragmento de una carta". El culto al árbol. De Alberto Nin Frías. Buenos Aires: Claridad, 1933. 13-314. Impreso.

Mistral, Gabriela. "Carta a Antonio Bórquez Solar: 18 de febrero de 1912". Benson Collection, U Texas Library, Austin, Texas. Impreso.

Mistral, Gabriela. "Carta a Eduardo Barrios: abril-mayo, 1917". Hebsburgh Library, U Notre Dame, Indiana. Impreso.

Mistral, Gabriela. "Cartas a Alberto Nin Frías más un fragmento sobre Sordello Andrea". El ojo atravesado. Eds. S. Guerra y V. Zondek. Santiago: LOM, 1998, p. 15-20. Impreso.

Mistral, Gabriela. "Cartas a Manuel Magallanes Moure, 1914-1923". Biblioteca de Humanidades de la Pontificia Universidad Católica de Chile, Campus San Joaquín, Santiago de Chile. Impreso.

Mistral, Gabriela. "Cartas a Maximiliano Salas Marchan [ago.-sept.] 1913". AEoooo1117; 1916, AE100109. Biblioteca Nacional de Chile. Web.

Mistral, Gabriela. Epistolario. Cartas a Eugenio Labarca 1915-1916. Ed. Raúl Silva Castro. Santiago: Ediciones Anales de la Universidad de Chile, 1957. Impreso. 
Mistral, Gabriela. Manuel en los labios por mucho tiempo. Epistolario entre Lucila Godoy Alcayaga y Manuel Magallanes Moure. Eds. M. E. Martínez Sanz y Luis Vargas Saavedra. Santiago: U Católica, 2005. Impreso.

Mistral, Gabriela. Vuestra Gabriela. Cartas inéditas con los Errázuriz, Echeñique, Tomic. Ed. Luis Vargas Saavedra. Santiago: Zig-Zag, 1995. Impreso.

Nin Frías, Alberto. Alexis, o el significado del temperamento urano. Madrid: Javier Morata, 1932. Impreso.

Nin Frías, Alberto. El árbol. Valencia: Sampere, 1909, 1910. Impreso.

Nin Frías, Alberto. "Carta a Gabriela Mistral: 20 nov. 1914". AEooo1524. Biblioteca Nacional de Chile. Web.

Nin Frías, Alberto. "Carta a Gabriela Mistral: 07 ago. 1934". AEooo8593. Biblioteca Nacional de Chile. Web.

Nin Frías, Alberto. El culto al árbol, ensayo de interpretación de la naturaleza de las plantas y sus efectos sobre el alma humana. Buenos Aires: Claridad, 1933. Impreso.

Nin Frías, Alberto. Homosexualismo creador. Madrid: Javier Morata, 1933. Impreso.

Nin Frías, Alberto. Marcos, amador de la belleza, o, la casa de los sueños: novela de un discípulo de Platón durante el Renacimiento (el libro del alma hermosa). Valencia: Sampere, 1909. Impreso.

Nin Frías, Alberto. "Reseña de la obra cultural de Alberto Nin Frías". Biblioteca Nacional de Uruguay, 1933. Impreso.

Nin Frías, Alberto. Sordello Andrea, sus ideas y pensares (novela de la vida interior). Valencia: Sampere, 1912. Impreso.

Peña, Karen Patricia. "Violence and Difference in Gabriela Mistral's Short Stories 1904-1911". Latin American Research Review 40.3 (2005): 68-96. Impreso.

Santelices, Isauro. Mi encuentro con Gabriela Mistral 19121957. Santiago: Editorial del Pacífico, 1972. Impreso.

Unamuno, Miguel de. 13 cartas inéditas de Miguel de Unamuno a Alberto Nin Frías. Ed. Pedro Badanelli. Buenos Aires: Mandrágora, 1962. Impreso.

Vaz Ferreira, María Eugenia. "Correspondencia con Alberto Nin Frías". Revista Biblioteca Nacional 12 (1976): 71-81. Impreso.

Vidal, Virginia "Marta Vergara, la irreverente". Anaquel Austral. Web. 